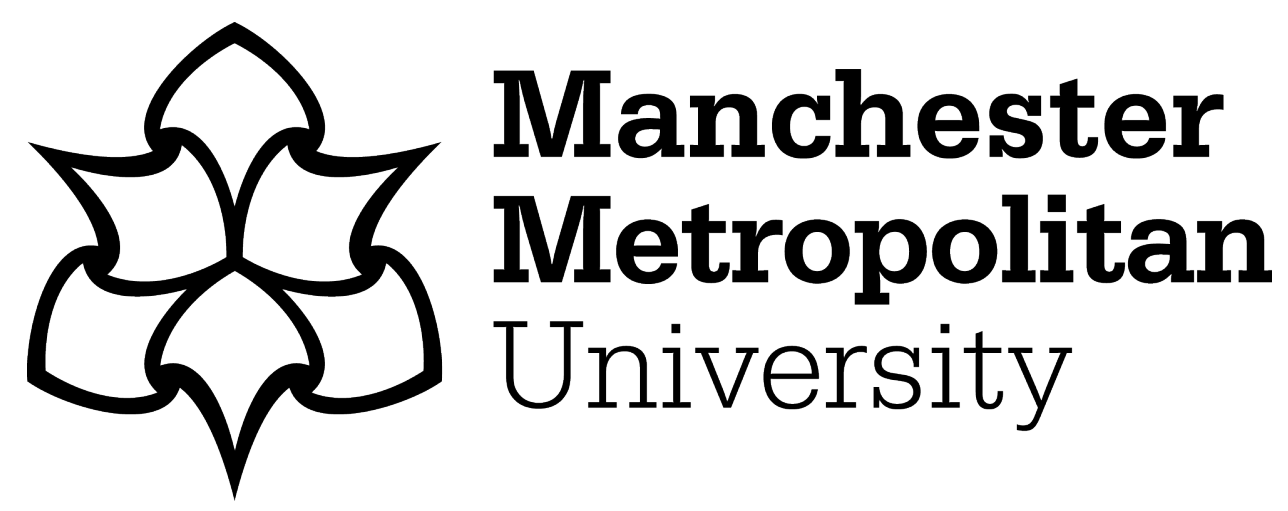

Davis, Nicholas (2018) Questioning the Goldwater Rule: Commentary on Lilienfeld, Miller, and Lynam. Perspectives on Psychological Science, 13 (1). pp. 31-32. ISSN 1745-6916

Downloaded from: https://e-space.mmu.ac.uk/619388/ Version: Accepted Version

Publisher: Association for Psychological Science/SAGE Publications DOI: https://doi.org/10.1177/1745691617733959

Please cite the published version 


\section{Questioning the Goldwater Rule: Commentary on Lilienfeld, Miller and Lynam}

Nick J. Davis, Department of Psychology, Faculty of Health Psychology and Social Care, Manchester Metropolitan University, Manchester M15 6GX, United Kingdom

E-mail: n.davis@mmu.ac.uk

To what extent might a person's mental state be public knowledge? In this issue, Lilienfeld, Miller, and Lynam (2017) discuss this important ethical question. The so-called Goldwater Rule is the commonly followed convention that a psychologist or psychiatrist should not comment on the mental state of a person whom they have not examined personally. The rule is currently under particular pressure given the fervent press speculation around the mental state of the U.S. President, Donald J. Trump.

Although it is common for media pundits to throw around such words as "narcissism" and "psychotic," such terms are accorded more weight when deployed by people qualified to use them. Yet if a person with political (or other) power has a mental state that may predispose them to harm others, should that possibility not be open to public debate? So the question addressed by Lilienfeld et al. is this: When is it acceptable to use professional opinion to discuss the mental state of a person whom one has never met? This is a thorny ethical question, and this article is an example of professional ethical enquiry done well.

Lilienfeld et al. argue that the Goldwater Rule is outdated. The basis of the rule is that in-person examination provides more reliable information about a person's mental state than remote examination, so a psychologist could not provide a competent diagnosis without having shared a room with that person. However, Lilienfeld et al. attack this claim from several angles. Research spanning decades has shown that both structured and unstructured interviews are susceptible to impression management by well-prepared patients and that these methods also have poor interrater reliability when used to make categorical diagnoses (Aboraya, Rankin, France, El-Missiry, \& John, 2006). Indeed, skipping an interview and making judgments based on other sources of data may lead to more reliable judgments (Porter, Brinke, \& Wilson, 2009). Lilienfeld et al. term this the interview fallacy, suggesting that there is a false equivalence with the physician's need for an in-person diagnosis of most physical disorders. ${ }^{1}$ In these days of comprehensive archival footage of public figures' speeches, of autobiographies, and of unfiltered Twitter accounts, access to rich information about a person's thought patterns is easier than ever, both from the person's own reports and from those of close friends and family members. Lilienfeld et al. make the compelling case that for many people in the public eye, we have the information available to make a categorical judgment about their mental status.

So if we can access a person's mental state, should we comment on it? This is the key ethical question that underpins the Goldwater Rule. Lilienfeld et al. argue that qualified professionals have a "duty to warn" when a person's mental state may lead to harm to those around them. Lilienfeld et al. argue that comment on the mental health of a public figure is acceptable only when that person has "substantial power over others." Lilienfeld et al. rightly apply this to senior politicians, but there will need to be a line drawn somewhere: Nonelected figures also have the potential to cause harm, including civil servants, heads of financial institutions, and even some 
celebrities. Clearly a person in command of the world's most powerful armed forces has the potential to cause great harm to others, and one could further argue that there is a public interest in knowing whether that person may make dangerous choices in high-pressure situations.

But what do we mean by "public interest"? This is a crucial term that needs clarification. I agree that a qualified psychologist with well-founded worries about the mental status of a public figure should make those worries known. But known to whom? It is not clear to me that the public interest is best served by making such comments on prime-time television. "Labeling" a person with a disorder is potentially stigmatizing, even when there is no evidence that a particular disorder makes a person unfit to perform their duties (e.g., Davidson, Connor, \& Swartz, 2006). Mental-health stigma has a high cost to the person being stigmatized; many employers are unwilling to hire a person who has been treated for mental ill-health (Sharac, McCrone, Clement, \& Thornicroft, 2010). No person should feel ashamed of having sought help for a psychological condition, any more than they should be ashamed of a physical condition; however this use of mental-health labeling as a slur perpetuates discrimination against people who have experienced psychological illness.

As Lilienfeld et al. point out, fitness to serve is a legal question and may be answered only through the processes of law. Most nations' constitutions allow for a leader's authority to be challenged. Psychologists can, and should, have some input to this process, but only in offering evidence-based opinion. Expert evidence already has a place in the legal system, where it can be questioned by legal experts on both sides of the court. There is therefore no value in holding these debates outside of the legal system. To do so risks reducing expert opinion to prurient speculation. Such unfounded comments may even expose such experts to a charge of libel.

In this issue, Lilienfeld, Miller, and Lynam offer a timely, detailed and well-argued position on the Goldwater Rule. I disagree with the authors that the Goldwater Rule is outdated; I believe that all people are entitled to privacy regarding their health status and that public forums are not the best arena to air debates on the mental status of a third party. However, the psychological sciences need debates such as these to establish firm ethical rules for the conduct of its practitioners and to ensure that our interactions with the wider public are based on the best evidence and the best concern for the welfare of all.

Declaration of Conflicting Interests

The author declared no conflicts of interest with respect to the authorship or the publication of this article.

Note

1. As an aside, I would point out that James Parkinson discussed six cases of the "shaking palsy" in his famous Essay (Parkinson, 1817), one of whom he saw only from across the street. Remote diagnosis may sometimes be possible. 


\section{References}

Aboraya, A., Rankin, E., France, C., El-Missiry, A., \& John, C. (2006). The reliability of psychiatric diagnosis revisited: The clinician's guide to improve the reliability of psychiatric diagnosis. Psychiatry, 3(1), 41-50.

Davidson, J. R., Connor, K. M., \& Swartz, M. (2006). Mental illness in U.S. presidents between 1776 and 1974: A review of biographical sources. Journal of Nervous and Mental Disease, 194, 47-51. doi:10.1097/01.nmd.0000195309.17887.f5

Lilienfeld, S., Miller, J., \& Lynam, D. (2017). The Goldwater Rule: Perspectives from, and implications for, psychological science. Perspectives on Psychological Science, 12,

Parkinson, J. (1817). An essay on the shaking palsy. London, England: Sherwood, Neely, and Jones.

Porter, S., Brinke, L., \& Wilson, K. (2009). Crime profiles and conditional release performance of psychopathic and non-psychopathic sexual offenders. Legal and Criminological Psychology, 14, 109-118.

Sharac, J., McCrone, P., Clement, S., \& Thornicroft, G. (2010). The economic impact of mental health stigma and discrimination: A systematic review. Epidemiology and Psychiatric Sciences, $19,223-232$. 